\title{
ORIGINAL
}

\section{Evaluation of the isokinetic muscle strength, balance and anaerobic performance in patients with young male hypogonadism}

\author{
Umit Aydogan $^{1)}$, Ali Eroglu ${ }^{2)}$, Halil Akbulut ${ }^{1)}$, Yavuz Yildiz ${ }^{2)}$, Deniz Engin Gok ${ }^{3)}$, Alper Sonmez ${ }^{4)}$, \\ Taner Aydin ${ }^{2)}$, Erol Bolu ${ }^{4)}$ and Kenan Saglam³) \\ 1) Gulhane Military Medical Academy, Department of Family Medicine, Ankara, Turkey \\ 2) Gulhane Military Medical Academy, Department of Sports Medicine, Ankara, Turkey \\ 3) Gulhane Military Medical Academy, Department of Internal Medicine, Ankara, Turkey \\ 4) Gulhane Military Medical Academy, Department of Endocrinology and Metabolic Diseases, Ankara, Turkey
}

\begin{abstract}
Hypogonadism is a clinical condition that occurs due to infrequent abnormalities in the hypothalamic-pituitarygonadal (HPG) axis in adolescence. Symptoms include weakening of muscle and bone strength. 30 young male patients with congenital hypogonadotropic hypogonadism (CHH) and 20 healthy young males were included in the present study. Quadriceps and hamstring muscle strength, balance and anaerobic performance capacities of the study group were measured both before and six months after testosterone replacement therapy (TRT). The strength of the extensor and flexor muscles of both legs showed a statistically significant increase in the isokinetic test values at $60^{\circ} / \mathrm{sec}$ and $180^{\circ} / \mathrm{sec}$ angular velocity $(p<0.05)$. When the parameters related to balance were investigated, a statistically significant difference was found for stability indices of left and right between pre-TRT and post-TRT ( $p=0.001$ for both comparisons). According to the patients' anaerobic performance measurement results, a statistically significant improvement $(p<0.001)$ was also found between pre-TRT and post-TRT values for each parameter. It was shown that TRT significantly increases muscle strength, balance, and anaerobic performance of patients with male CHH. As a result, we absolutely recommend the use of TRT in patients with male $\mathrm{CHH}$.
\end{abstract}

Key words: Hypogonadism, Testosterone replacement therapy, Muscle strength, Postural balance, Anaerobic performance

TESTOSTERONE is synthesized from cholesterol and is the most important male sex hormone in the body [1]. It shows anabolic effects similar to other steroid hormones, and plays an important role in reproductive function and development of secondary sexual characteristics. A properly functioning hypotahalamic-pituitary-gonadal (HPG) axis requires a perfect harmony and is essential for sexual maturation and development of reproductive functions. Interruption at any level of this axis may result in hypogonadism [2]. Young male patients with congenital hypogonadotropic hypogonadism $(\mathrm{CHH})$ often consult their physicians because of the absence or incomplete pubertal development resulting in impaired secondary sexual characteris-

Submitted Sep. 8, 2011; Accepted Jan. 4, 2012 as EJ11-0242

Released online in J-STAGE as advance publication Jan. 26, 2012

Correspondence to: Umit Aydogan, Gulhane Military Medical Academy, Department of Family Medicine, 06018, Etlik, Ankara, Turkey. E-mail: uaydogan06@gmail.com tics. Furthermore, decreased muscle mass increases the symptoms of malaise, fatigue, and anxiety, and also significantly reduces the quality of life in male patients with $\mathrm{CHH}$ [3]. To restore this imbalance, testosterone replacement therapy (TRT) is one of the most commonly prescribed therapies in male hypogonadism [4, 5]. Testosterone increases muscle mass and bone formation by ensuring a positive nitrogen balance [6]. In the case of testosterone inadequacy, patients may suffer from osteoporosis and severe muscle weakness [7, 8]. Either replacement of testosterone at physiological doses to patients with male hypogonadism or administration of supraphysiological testosterone doses to healthy individuals is associated with an increased muscle mass [9]. However, there is no consensus on mechanisms by which testosterone influences muscle mass. It has been estimated that both muscle fiber hypertrophy and myocyte hyperplasia are responsible for this increase. Tucek et al., found testosterone to 
stimulate weight gain of the levator ani muscle in rats by $15 \%$. This muscle hypertrophy was accompanied by the increase in the number of muscle fibers [10].

One should have adequate and effective muscle volume, muscle strength and endurance level for daily movements and regular physical activity. Muscle strength and endurance can be measured with different tests such as isokinetic measurement, 30-second anaerobic test, and balance testing system [11, 12]. An increase in muscle mass has been demonstrated in several studies of TRT $[5,13]$. On the other hand, studies on muscular strength and endurance levels are quite rare and are mainly focused on patients of advance age $[4,5]$. As far as we know, there is no scientific study examining muscle strength and endurance in young male patients with CHH. Unlike previous studies, young male patients newly diagnosed with $\mathrm{CHH}$ and who have never had TRT before, were included in the present study. Lower extremity muscle strength and endurance were compared both preTRT and post-TRT.

\section{Material and Method}

The study was performed between June 2009 and November 2010 in the outpatient clinics of the Gulhane Military Medical Academy School of Medicine, Departments of Endocrinology and Metabolism. Patients with CHH ( $\mathrm{n}=30$, mean age: $21.03 \pm 0.93$ years) and healthy control subjects ( $\mathrm{n}=20$, mean age: $22.15 \pm 2.35$ years) were enrolled. The study protocols were approved by the Ethics Committee of the Gulhane Military Medical Academy, Ankara, Turkey. Patients were informed about the purpose and scope of the study. All subjects voluntarily accepted to participate in the study and written informed consent was obtained at the beginning.

The diagnosis of $\mathrm{CHH}$ was based on a failure to undergo spontaneous puberty before 18 years of age and was confirmed by low serum total testosterone levels with normal or low gonadotropin levels. Additional criteria used for diagnosis included the absence of a pituitary or hypothalamic mass lesion on magnetic resonance imaging, presence of a gonadotropin response to repetitive doses of gonadotropin-releasing hormone, and a normal karyotype (46, XY). All patients enrolled in the study had Tanner stages of 1 to 2, bone ages below 18 years, and FSH, LH and total testosterone levels below the cut-off values
(15 mIU/mL, $10 \mathrm{mIU} / \mathrm{mL}$ and $300 \mathrm{ng} / \mathrm{dL}$ respectively). The control subjects had normal pubertal development and normal serum total testosterone, FSH and LH levels. None of the patients and the control subjects had any acute or chronic disorders or was under any specific medication including over the counter drugs. The height, weight and waist circumferences of the patients and control subjects were measured by their underwear. Body mass index (BMI) was computed as the ratio of weight to the square of height $\left(\mathrm{kg} / \mathrm{m}^{2}\right)$. BMI was categorized as underweight $\left(<18.5 \mathrm{~kg} / \mathrm{m}^{2}\right)$, normal $(18.5$ $\left.24.9 \mathrm{~kg} / \mathrm{m}^{2}\right)$, overweight $\left(25-29.9 \mathrm{~kg} / \mathrm{m}^{2}\right)$, and obese $\left(>30 \mathrm{~kg} / \mathrm{m}^{2}\right)$. Body fat index (BFI, Fat \%) was calculated by the Tanita ${ }^{\mathrm{TM}}$ device, which was also calibrated regularly. Pubertal developments of the patients were assessed according to the Tanner Stages.

\section{Laboratory measurements}

For biochemical analyses, all blood samples were collected after an overnight fasting from an antecubital vein, between 08.00 and 09.00 AM. The samples were centrifuged for 15 minutes at $4000 \mathrm{rpm}$, aliquoted and immediately frozen at $-80^{\circ} \mathrm{C}$ for further analyses. Total testosterone, follicle-stimulating hormone (FSH), and luteinizing hormone $(\mathrm{LH})$ were measured by chemiluminescence immunoassay method using a Unicell Beckman \& Coulter DXI 800 model device. After the calibration of the weighing equipment, anthropometric measurements of patients (weight and height) were performed in the morning while they were standing in an upright position with an empty stomach and without shoes and clothing.

\section{Testosterone replacement therapy}

After enrolment, the patients were treated with an oil-based injectable blend of four esterized testosterone compounds (Sustanon $250 \mathrm{mg} ; 30 \mathrm{mg}$ testosterone propionate, $60 \mathrm{mg}$ testosterone phenylpropionate, 60 $\mathrm{mg}$ testosterone isocaproate and $100 \mathrm{mg}$ testosterone decanoate) injected for 3 weeks. The blood samples for the evaluation of the baseline parameters were taken before the first testosterone injection. The patients were then reevaluated in the 6th month of treatment. The follow-up visits for the testosterone injection regiment group were arranged on the days before the next testosterone injection. Therefore, the time points for taking the blood samples were similar for all the patients. 


\section{Measurement of muscle strength with isokinetic dynamometer}

The knee to be tested was placed on the knee flexionextension plate of the Cybex Norm device and secured with Velcro straps, according to the manufacturer's instructions for isolating knee flexion and knee extension. The length of the dynamometer was adapted to the length of the knee of each subject. To synchronise themselves with the testing device, subjects were instructed to perform three active repetitions of knee movement ranging from maximal flexion to maximal extension. Standard stabilisation strapping was placed across the distal thigh and chest, and placements were limited to grasping the waist stabilisation strap. Before the testing session started, the subject was allowed a 10 minute warm up at a light intensity (less than $50 \mathrm{~W}$ ) on a cycle ergometer, followed by a 30 second stretch of the quadriceps and hamstring muscles. Selection of the extremity was random. The same investigator performed all the tests. Subjects were encouraged to give $100 \%$ effort and received positive feedback during testing. In order to adapt to the test conditions, patients were allowed three submaximal contractions of the quadriceps and hamstring muscle group at the beginning of the tests. They were given five maximal contractions at $60 \% \mathrm{sec}$ and 15 maximal contractions at $180 \%$ sec for each test condition. The best peak torque and power contraction of the five and 15 test contractions for each test condition were collected for data analysis. Between each condition, the subjects were allowed to rest for one minute and gravitational corrections were performed.

\section{Balance measurement parameters}

Measurements of balance and coordination were performed using the Biodex device (Balance System SD тм, USA) with postural stability mode. The information about the test procedure was given to participants before the test. The balance positions of the foot were determined and measurements were performed both before the trial and during the test on the platform. For ensuring compliance with the test, participants on the right and left foot $6 / 6$ for a period of $60 \mathrm{sec}$ at the level of difficulty.

\section{Anaerobic performance measurement values}

Anaerobic performance parameters were measured by the Wingate anaerobic performance testing system. The name, body weight, height, age and contact infor- mation of the participants were recorded on a computer. The bicycle seat height was set according to the participants' knee flexion angle of $15-20^{\circ}$. Then, 75 grams of weight per kilogram of body weight was loaded onto the bicycle's weight scale. Firstly, without any weight load, all the participants were asked to pedal at maximum speed. After the two-minute resting period, the test was started. During the test, participants were asked to pedal for 30 seconds at maximum speed and maximum resistance. After the test, peak and average power were assessed.

\section{Statistical analysis}

All data were recorded on a computer database and analyzed using the SPSS 11.0 package program (SPSS, Inc., Chicago, IL, USA). Results are expressed as mean \pm S.D. Intra-group changes at two time points were analyzed by paired samples $t$-test and chi-square. Intergroup differences were analyzed by the Student's $t$-test. Differences were considered significant at $p<0.05$.

\section{Results}

The demographic parameters and the laboratory values of the patients and the healthy control group are given in Table 1. According to the data, the patients had similar BMI, but significantly higher BFI when compared to the healthy control group. Six months of TRT appears to increase both weight and the height ( $p=0.046$ and $p=0.068$ respectively) but significantly decreases the BFI values $(p<0.001)$ of the patients, along with a significant improvement in the Tanner stages. These results show that non-fat mass is increased in patients with $\mathrm{CHH}$, due to the six months of TRT.

The pre-TRT extension and flexion peak torques of both extremities were significantly lower in the patients when compared to those of the control subjects (Table 2). All parameters of the patients were significantly improved ( $p<0.001$ for all) after six months of TRT. There were no significant differences when the post-TRT extension and flexion peak torques of both extremities were compared with those of the healthy control subjects. The antero-posterior stability index (API), mediolateral stability index (MSI) and overall stability index (OSI) measures of the patients were not significantly different from those of the healthy controls. After the TRT, the OSI values decreased in both right and left lower extremities $(p<0.001$ and $p$ 
Table 1 The demographic and hormonal characteristics of the patients and the healthy control group.

\begin{tabular}{|c|c|c|c|c|c|}
\hline & \multicolumn{2}{|c|}{ Study Group } & \multirow[b]{2}{*}{$\begin{array}{l}\text { Control Group } \\
\quad(n=20)\end{array}$} & \multirow[b]{2}{*}{$p^{1}$} & \multirow[b]{2}{*}{$p^{2}$} \\
\hline & $\begin{array}{l}\text { Pre-TRT } \\
(\mathrm{n}=30)\end{array}$ & $\begin{array}{c}\text { Post-TRT } \\
(\mathrm{n}=30)\end{array}$ & & & \\
\hline Age (yr) & $21.03 \pm 0.93$ & & $22.15 \pm 2.35$ & 0.371 & \\
\hline Height (cm) & $172.54 \pm 8.12$ & $174.21 \pm 8.44$ & $174.15 \pm 5.81$ & 0.027 & 0.046 \\
\hline Weight (kg) & $68.60 \pm 11.96$ & $70.40 \pm 13.83$ & $70.30 \pm 8.20$ & 0.044 & 0.068 \\
\hline BMI $\left(\mathrm{kg} / \mathrm{m}^{2}\right)$ & $23.10 \pm 3.07$ & $23.57 \pm 3.41$ & $23.18 \pm 2.45$ & 0.923 & 0.291 \\
\hline BFI (Fat \%) & $15.73 \pm 3.60$ & $14.08 \pm 3.44$ & $13.26 \pm 4.30$ & 0.001 & $<0.001$ \\
\hline Total Testosterone (ng/dL) & $65.08 \pm 56.32$ & $338.59 \pm 231.63$ & $482.56 \pm 119.67$ & $<0.001$ & $<0.001$ \\
\hline $\mathrm{FSH}(\mathrm{mIU} / \mathrm{mL})$ & $0.63 \pm 0.34$ & $0.95 \pm 1.35$ & $5.43 \pm 1.19$ & $<0.001$ & 0.269 \\
\hline LH (mIU/mL) & $0.34 \pm 0.29$ & $0.82 \pm 1.65$ & $5.44 \pm 1.05$ & $<0.001$ & 0.189 \\
\hline Tanner Stage & $1.5 \pm 0.5$ & $3.5 \pm 05$ & $5.0 \pm 0.00$ & $<0.001^{*}$ & $<0.001^{*}$ \\
\hline
\end{tabular}

Values are given as mean \pm standard deviation. BMI, Body mass index; BFI, Body fat index; FSH, Follicle-stimulating hormone; LH, luteinizing hormone; TRT, Testosterone replacement therapy $p^{1}$ :Pre-TRT vs. control group, independent-samples $t$-test $p^{2}$ :Pre-TRT vs. post-TRT group, paired-samples $t$-test ${ }^{*}$ chi-square

Table 2 The comparison of the lower extremity isokinetic muscle strength, balance and anaerobic performance parameters of the patients and the control group.

\begin{tabular}{|c|c|c|c|c|c|c|c|c|}
\hline & & & \multicolumn{2}{|c|}{ Study Group } & \multirow{2}{*}{$\begin{array}{l}\text { Control Group } \\
\qquad(\mathrm{n}=30)\end{array}$} & \multirow[b]{2}{*}{$p^{1}$} & \multirow[b]{2}{*}{$p^{2}$} & \multirow[b]{2}{*}{$p^{3}$} \\
\hline & & & $\begin{array}{c}\text { Pre-TRT } \\
(\mathrm{n}=30)\end{array}$ & $\begin{array}{l}\text { Post-TRT } \\
(\mathrm{n}=30)\end{array}$ & & & & \\
\hline \multirow{4}{*}{ Right } & EXPT & $60 \% / \mathrm{sec}$ & $90.90 \pm 24.71$ & $108.30 \pm 29.39$ & $120.20 \pm 39.06$ & 0.002 & 0.225 & $<0.001$ \\
\hline & $(\mathrm{Nm})$ & $180^{\circ} / \mathrm{sec}$ & $55.93 \pm 17.21$ & $68.70 \pm 16.31$ & $69.50 \pm 20.35$ & 0.014 & 0.878 & $<0.001$ \\
\hline & FXPT & $60 \% / \mathrm{sec}$ & $57.40 \pm 19.62$ & $73.66 \pm 27.15$ & $74.60 \pm 22.11$ & 0.006 & 0.899 & $<0.001$ \\
\hline & $(\mathrm{Nm})$ & $180^{\circ} / \mathrm{sec}$ & $48.73 \pm 17.45$ & $57.76 \pm 17.28$ & $67.05 \pm 20.19$ & 0.001 & 0.088 & $<0.001$ \\
\hline \multirow{4}{*}{ Left } & EXPT & $60^{\circ} / \mathrm{sec}$ & $85.20 \pm 25.99$ & $101.53 \pm 31.28$ & $114.80 \pm 36.56$ & 0.002 & 0.176 & $<0.001$ \\
\hline & $(\mathrm{Nm})$ & $180^{\circ} / \mathrm{sec}$ & $53.43 \pm 15.33$ & $64.30 \pm 17.89$ & $67.70 \pm 21.05$ & 0.008 & 0.543 & $<0.001$ \\
\hline & FXPT & $60^{\circ} / \mathrm{sec}$ & $57.00 \pm 19.72$ & $70.90 \pm 24.07$ & $72.90 \pm 18.37$ & 0.006 & 0.754 & $<0.001$ \\
\hline & $(\mathrm{Nm})$ & $180^{\circ} / \mathrm{sec}$ & $47.80 \pm 14.70$ & $58.80 \pm 16.21$ & $60.20 \pm 15.19$ & 0.006 & 0.761 & $<0.001$ \\
\hline \multirow{3}{*}{ Right } & & API & $1.43 \pm 0.46$ & $1.39 \pm 0.51$ & $1.73 \pm 0.68$ & 0.073 & 0.052 & 0.537 \\
\hline & & MSI & $1.31 \pm 0.50$ & $1.26 \pm 0.54$ & $1.57 \pm 0.52$ & 0.083 & 0.047 & 0.374 \\
\hline & & OSI & $2.09 \pm 0.62$ & $1.77 \pm 0.59$ & $2.31 \pm 0.79$ & 0.284 & 0.008 & $<0.001$ \\
\hline \multirow{3}{*}{ Left } & & API & $1.39 \pm 0.50$ & $1.41 \pm 0.53$ & $1.63 \pm 0.57$ & 0.131 & 0.171 & 0.800 \\
\hline & & MSI & $1.24 \pm 0.43$ & $1.25 \pm 0.48$ & $1.44 \pm 0.59$ & 0.183 & 0.289 & 0.838 \\
\hline & & OSI & $1.88 \pm 0.66$ & $1.65 \pm 0.56$ & $2.12 \pm 0.50$ & 0.168 & 0.004 & 0.058 \\
\hline \multicolumn{3}{|c|}{ PPO (W/Kg) } & $6.17 \pm 1.44$ & $7.52 \pm 1.91$ & $11.80 \pm 1.69$ & $<0.001$ & $<0.001$ & $<0.001$ \\
\hline \multicolumn{3}{|c|}{ MPO (W/Kg) } & $3.49 \pm 1.02$ & $4.05 \pm 0.93$ & $6.57 \pm 0.93$ & $<0.001$ & $<0.001$ & $<0.001$ \\
\hline \multicolumn{3}{|c|}{$\operatorname{MinPO}(\mathrm{W} / \mathrm{Kg})$} & $1.95 \pm 0.87$ & $2.37 \pm 0.85$ & $2.85 \pm 0.75$ & $<0.001$ & 0.046 & $<0.001$ \\
\hline
\end{tabular}

The values are given as mean \pm standard deviation. EXPT, Extantion peak torque; FXPT, Flexion peak torque; API, Anteroposterior stabilite index; MSI, Mediolateral stabilite indeks; OSI, Overall stability index; PPO, Peak power output; MPO, Mean power output; MinPO, Minimum power output; W, Watt; Kg, Kilogram; TRT, testosterone replacement therapy. $p^{1}$ : PreTRT study group vs. control group, independent-samples $t$-test $p^{2}$ : Post-TRT study group vs. control group, independent-samples $t$-test $p^{3}$ : Pre-TRT study group $v s$. post-TRT study group, paired-samples $t$-test

$=0.058$ respectively) (Table 2$)$. When the post-TRT values were compared with those of the healthy control subjects, the OSI values of both extremities were significantly lower than the control subjects $(p=0.008$ and $p=0.004$ respectively). In addition, the API and MSI values of the right lower extremity were slightly lower than the control subjects ( $p=0.052$ and $p=0.047$ respectively), while those of the left lower extremities were not significantly different.

Anaerobic performance parameters were also measured before and after TRT in hypogonadal patients. The peak power output (PPO), mean power output (MPO) and minimum power output (Min PO) values of the patients were significantly lower than those of 
the control subjects ( $p<0.001$ for all).

The PPO, MPO and Min PO values were significantly improved after six months of TRT ( $p<0.001$ for all), but still lower when compared to those of the control subjects $(p<0.001$ for PPO and MPO, $p=0.046$ for Min PO) (Table 2).

\section{Discussion}

The results of the present study show that young patients with $\mathrm{CHH}$ who have never had TRT before, have poor lower limb isokinetic muscle strength, balance and anaerobic performance parameters when compared to age and BMI matched healthy control subjects. TRT for six months significantly improved the lower limb isokinetic muscle strength, anaerobic performance and balance parameters in these patients. The post-TRT muscle strength of the patients was similar to those of the values of the healthy controls. These results show that the positive effects of TRT on muscle strength occur in a relatively short period of TRT.

Isokinetic exercises improve muscle strength and health-related quality of life $[14,15]$. Isokinetic muscle measurements are often used in sports medicine to assess the healing process $[15,16]$. In the present study, isokinetic quadriceps and hamstring muscle strengths were measured and the response to TRT was evaluated. These two muscle groups were mainly examined because they are the major muscles involved in daily activities such as walking and running. As a result, both right and left quadriceps and hamstring muscle mass were significantly increased after TRT. In addition, this increase was significant at angular velocities of $60^{\circ} / \mathrm{sec}$ and $180^{\circ} / \mathrm{sec}$ in both extremities. Not all the studies however, show similar results for the TRT. A previous report showed that oral TRT for 6 months had no positive effect on isometric muscle strength in patients with late-onset male hypogonadism [7]. This may be due to the intensity and duration of muscular exercise, as well as patient age, muscle strength, and the measurement techniques. Another reason may be that young hypogonadal men are found to benefit substantially from of TRT. However, this benefit tends to decrease with age due to comorbid diseases that increase with aging [17].

When the balance parameters in hypogonad patients who hadn't received TRT were compared to those in the control group, no significant difference was found. However, after these patients received TRT, there was a significant improvement in OSI values. The body's balance is established according to the information from visual, auditory and deep sensory pathways processed in the central nervous system. In particular, the transmission of the information through the cerebellum to dorsal spinocerebellar tract plays an important role here. In addition, proprioceptive senses also contribute to the transmission to top centers in the central nervous system $[6,9]$. In this sense, it could be argued that the increase of the balance parameters in male patients with hypogonadism was due to increase in the muscle strength and endurance capacity. Physiologically, it should be expected that a positive relationship between the balance parameters of the body posture and the muscle strength might exist. It is important that there was a partial improvement in some of the balance parameters within six months of TRT. Overall, the lower than expected improvement in balance parameters may be attributed to the relatively short period of TRT. The follow up data is necessary in order to clarify the longer term effects of TRT on balance parameters.

One of the functional tests used to determine lower extremity muscular strength and power is the Wingate anaerobic power test. The results of the Wingate anaerobic power test show that the anaerobic capacity of the patients with $\mathrm{CHH}$ significantly improves after the TRT. This might be due to the hypertrophic effect of testosterone on muscle cells which causes an increase in the anaerobic capacity in male hypogonadal patients. So far there have been no reports about the positive effect of TRT on the anaerobic capacity in patients with hypogonadism. Further studies are warranted to clarify the positive effects of TRT on anaerobic performance in men with hypogonadism.

According to the results of the study, BFI values significantly decreased while there were no significant alterations in the BMI values. The data supports the theory that muscle mass increases due to TRT. The data presented in the former reports also support the findings in our study. A review of studies on the effects of TRT between 1998 and 2004, demonstrated that TRT leads to reductions in BFI [18]. Several other studies reported benefits in testosterone supplementation in increasing muscle strength and lean body mass while decreasing fat mass [19-21]. Physiologically, testosterone increases muscle strength by increasing nitrogen uptake. By acting on pluripotent stem cells, androgens are responsible for the growth and change of vascular smooth muscle cells, which results in increased muscle strength [22]. 
This study may have several limitations. The results can only show that short term TRT improves muscle strength, balance and anaerobic performance. Follow up studies are needed to see whether the effects of TRT will endure in the long term. Also, the sample size may look small in number. But the strict enrolment criteria of the study; young and treatment naive patients of $\mathrm{CHH}$ free of chronic metabolic disorders, allow us to clearly understand the effect of TRT without being confounded by other factors. This study is also the first one to evaluate the effect of TRT on the anaerobic capacity of patients.

\section{Conclusion}

In conclusion, the results of the present study show that, patients with $\mathrm{CHH}$ have significantly worse lower extremity muscle strength and anaerobic performance values when compared to age and BMI matched healthy counterparts. Six months of TRT therapy significantly improves the above parameters in these patients with a significant increase in lean body mass. Further studies with longer follow up periods are warranted to understand the durability of the effects of TRT.

\section{References}

1. Harman SM, Metter EJ, Tobin JD, et al. (2001) Longitudinal effects of aging on serum total and free testosterone le-vels in healthy men. Baltimore Longitudinal Study of Aging. J Clin Endocrinol Metab 86: 724-731.

2. Vigano A, Piccioni M, Trutschnigg B, Hornby L, Chaudhury P, Kilgour R (2010) Male hypogonadism associated with advanced cancer: a systematic review. Lancet Oncol 11: 679-684.

3. Moncada I (2006) Testosterone and men's quality of life. Aging Male 9: 189-193.

4. Page ST, Amory JK, Bowman FD, Anawalt BD, Matsumoto AM, Bremner WJ, Tenover JL (2005) Exogenous Testosterone ( $\mathrm{T}$ ) Alone or with Finasteride Increases Physical Performance, Grip Strength, and Lean Body Mass in Older Men with Low Serum T. $J$ Clin Endocrinol Metab 90: 1502-1510.

5. Emmelot-Vonk MH, Verhaar HJ, Nakhai Pour HR, Aleman A, Lock TM, Bosch JL, Grobbee DE, van der Schouw YT (2008) Effect of testosterone supplementation on functional mobility, cognition, and other parameters in older men: a randomized controlled trial. JAMA 299: 39-52.

6. Ganong WF (1996) Gonadlar: Ureme sisteminin gelismesi ve gorevleri. In: Dikmenoglu N, Balkanci D (çeviri editorleri) Tibbi Fizyoloji (17. bask1). Baris Kitabevi, Ankara: 528-531 (In Turkish).

7. Karasek M, Kochanski JW, Bierowiec J, Suzin J, Swietoslawski J (2000) Testosterone levels and bone mineral density in young healthy men and in young infertile patients. Neuro Endocrinol Lett 21: 25-29.

8. Ebeling PR (1998) Osteoporosis in men. New insights into aetiology, pathogenesis, prevention and management. Drugs Aging 13: 421-434.

9. Guyton AC (1996) Somatik duyular: 1. mekanoreseptif duyular. In: Cavusoglu H, Gokhan N (çeviri editörleri) Tibbi Fizyoloji (1. baskı). Nobel Tıp Kitabevi, Istanbul: 830-834 (In Turkish).
10. Tucek S, Kostírová D, Gutmann E (1976) Testosteroneinduced changes of choline acetyl-transferase and cholinesterase activities in rat levator ani muscle. $J$ Neurol Sci 27: 353-362.

11. Sekir U, Yildiz Y, Hazneci B, Ors F, Aydin T (2007) Effect of isokinetic trainig on strenght, functionality and proprioception in athletes with functional ankle instability. Knee Surg Sports Traumatol Arthrosc 15: 654-664.

12. Yildiz Y, Aydin T, Sekir U, Cetin C, Ors F, Kalyon TA (2003) Relation between isokinetic muscle strength and functional capacity in recreational athletes with chondromalacia patellae. Br J Sports Med 37: 475-479.

13. Gruenewald DA, Matsumoto AM (2003) Testosterone supplementaion therapy for older men: potential benefits and risks. J Am Geriatr Soc 51: 101-115.

14. Alaca R, Yilmaz B, Goktepe AS, Mohur H, Kalyon TA (2002) Efficacy of isokinetic exercise on functional capacity and pain in patellofemoral pain syndrome. Am J Phys Med Rehabil 81: 807-813.

15. Kannus P (1994) Isokinetic evaluation of muscular performance: implications for muscle testing and rehabilitation. Int J Sports Med 15 (Suppl 1): S11-S18.

16. Ly LP, Handelsman DJ (2002) Muscle strength and ageing: methodological aspects of isokinetic dynamometry and androgen administration. Clin Exp Pharmacol Physiol 29: 37-47.

17. Bhasin S, Basaria S (2011) Diagnosis and treatment of hypogonadism in men. Best Pract Res Clin Endocrinol Metab 25: 251-270.

18. Makshida N, Shah J, Yan G, Fisch H, Shabsigh R (2005) Hypogonadism and metabolic syndrome: implications for testosterone therapy. J Urol 174: 827-834.

19. Tenover JS (1992) Effects of testosterone supplementation in the aging male. J Clin Endocrinol Metab 75: 1092-1098.

20. Sih R, Moorley JE, Kaiser FE, Perry HM, Patrick P, Ross C (1997) Testosterone replacement in older hypog- 
onadal men: a 12 month randomized controlled trial. $J$ Clin Endocrinol Metab 82: 1661-1667.

21. Strenbach H (1998) Age-testosterone decline in Men: Clinical Issues for Psychiatry. Am J Psychiatry 155: 1310-1318.
22. Singh R, Artaza JN, Taylor WE, Gonzalez-Cadavid NF, Bhasin S (2003) Androgens stimulate myogenic differentiation and inhibit adipogenesis in $\mathrm{C} 3 \mathrm{H}$ 10T1/2 pluripotent cells through an androgen receptor-mediated pathway. Endocrinology 144: 5081-5088. 